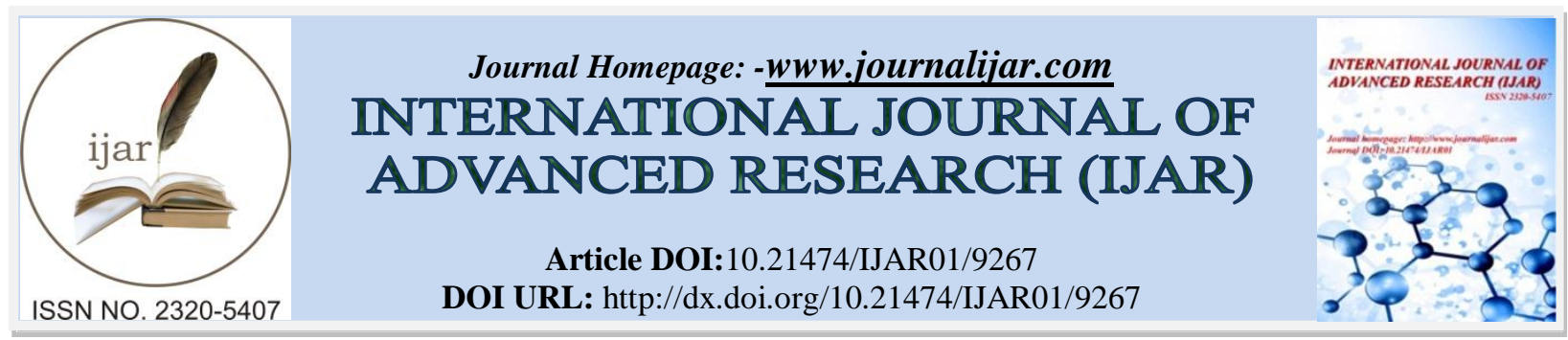

RESEARCH ARTICLE

\title{
RADIOLOGICAL IMAGING IN A PATIENT WITH COMPLETE ANDROGEN INSENSITIVITY SYNDROME.
}

Dr. Harshvardhan Singh Rathore ${ }^{1}$, Dr. Pratik Patil ${ }^{2}$, Dr. Madanmanmohan ${ }^{3}$ and Dr. Neeti Mathur ${ }^{4}$

1. Resident ( $3^{\text {rd }}$ year), Department of Radiodiagnosis, Dr. D.Y. Patil Medical College, Navi Mumbai.

2. Assosiate Professor, Department of Radiodiagnosis, Dr. D.Y. Patil Medical College, Navi Mumbai.

3. Head of Departent, Department of Radiodiagnosis, Dr. D.Y. Patil Medical College, Navi Mumbai.

4. Professor, Department of Radiodiagnosis, Dr. D.Y. Patil Medical College, Navi Mumbai.

\section{Manuscript Info}

.........................

Manuscript History

Received: 12 April 2019

Final Accepted: 14 May 2019

Published: June 2019

Key words:-

Androgen insensitivity

syndrome,Testicular feminisation

syndrome,Mullerian duct derivatives.

\section{Abstract}

Androgen insensitivity syndrome (AIS), initially referred as the testicular feminisation syndrome, results from end-organ resistance to testosterone.

It is classified into complete (CAIS), partial (PAIS), or mild (MAIS) with different radiological imaging findings in all of them.

Complete androgen insensitivity syndrome(CAIS) is an X-linked recessive androgen receptor disorder which is characterized by a female phenotype with an male (XY) karyotype. Individuals have normal female external genitalia but absence of the Mullerian duct derivatives, (i.e) absence of Fallopian tubes, uterus, cervix, and the proximal part of the vagina, with presence of intraabdominal, labial, or inguinal testes.

The estimated prevalence of this syndrome is between $1: 1,00,000$.

Radiological imaging is important both to diagnose and also to localize the gonads prior to surgical treatment.

In this paper, we present a case of complete androgen insensitivity syndrome in adult women who presented with complaints of primary amenorrhea and infertility.

Copy Right, IJAR, 2019,. All rights reserved.

\section{Introduction:-}

Complete androgen insensitivity syndrome (CAIS) is a rare disorder of sex development, with prevalence of 1: $1,00,000$. It is due to loss of function mutations of the androgen receptor gene in individuals with an XY genotype. Individuals are phenotypically female with normal female external genitalia. The most common presenting symptom of CAIS is primary amenorrhea.

This syndrome was first described in 1953 by Morris, an American gynecologist, and called it as "testicular feminization syndrome". However the name was later changed to androgen insensitivity syndrome.

Diagnosis is obtained when a male karyotype is found in an individual with a female phenotype. The patient has a female gender identity with normal breast development, little pubic and axillary hair, primary amenorrhea, and a blind-ending vagina. 


\section{Case history}

We report a case of a 20 year old Indian, married since 2 years and presented with chief complaints of primary amenorrhea and infertility. On clinical examination a well-developed breast with absence of axillary and pubic hair were noticed. She had a normal female external genitalia with blindly ending vagina. There were no ovaries or any other internal female genital organs identifiable.

The patient was then referred to our department for MRI pelvis.

MRI pelvis revealed following findings. There was non -visualization of the uterus and cervix

Bilateral ovaries were also not seen in the adnexa. No adnexal solid / cystic mass lesion was seen.

A small suspicious blind ending / atretic structure was seen in the recto-vaginal pouch which was suggestive of ? pseudovagina.

Two well defined lobulated soft tissue lesions were seen involving the bilateral inguinal canals measuring $28 \mathrm{x}$ $14 \mathrm{~mm}$ on the right and $30 \times 16 \mathrm{~mm}$ on the left side which were suggestive of testes.

\section{Discussion:-}

1. Complete androgen insensitivity syndrome can be detected during the first few days of life when there is discrepancy between the prenatal sex prediction and the phenotype at birth, or in the case of monolateral or bilateral inguinal hernia in a young girl containing testes.

2. Intra-abdominal location of the testes is a well-known cause of malignany, but prepubertal tumors are usually rare, with an incidence of $0.8 \%$ whereas in adults the risk of malignancy increases to almost $14 \%$.

3. The current management is to delay gonadectomy until after completion of puberty because there is no substantial risk of malignancy before puberty. However, few individuals choose to keep their gonads into adult life for a variety of reasons.

4. Imaging plays a crucial role in its diagnosis, and detection of the gonads before surgical treatment. Transabdominal ultrasonography (US) is usually the first-line examination in evaluating the absence of Müllerian structures and the location of the testes. However MRI is investigation of choice for it.

\section{Differential Dignosis-}

1. Mayer-Rokitansky-Kuster-Hauser (MRKH) syndrome

2. Swyer syndrome

\section{Conclusion:-}

1. MRI is the gold standard for investigation because of its higher accuracy in the evaluation of Müllerian duct abnormalities due to its detailed anatomic information, superior tissue characterization, and multiplanar capability. It plays a key role in the planning of gonadectomy by revealing the presence and location of the testes .

2. Karyotyping should always be done in all female infants diagnosed with a bilateral inguinal hernia because it is rare in normal female infants and associated with CAIS in 1-2\% of cases during infancy. 


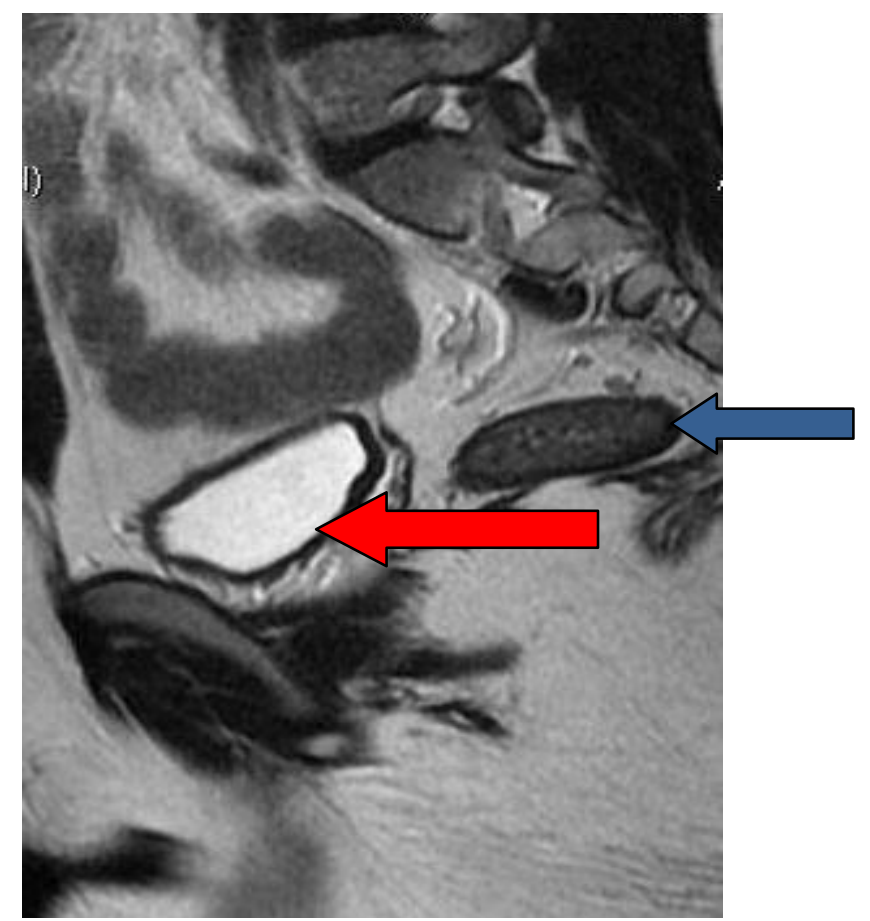

Fig 1:-Sagital T2W image of pelvis showing urinary bladder anteriorly ( Red arrow) and rectum posteriorly ( Blue arrow) with non -visualization of uterus and cervix.

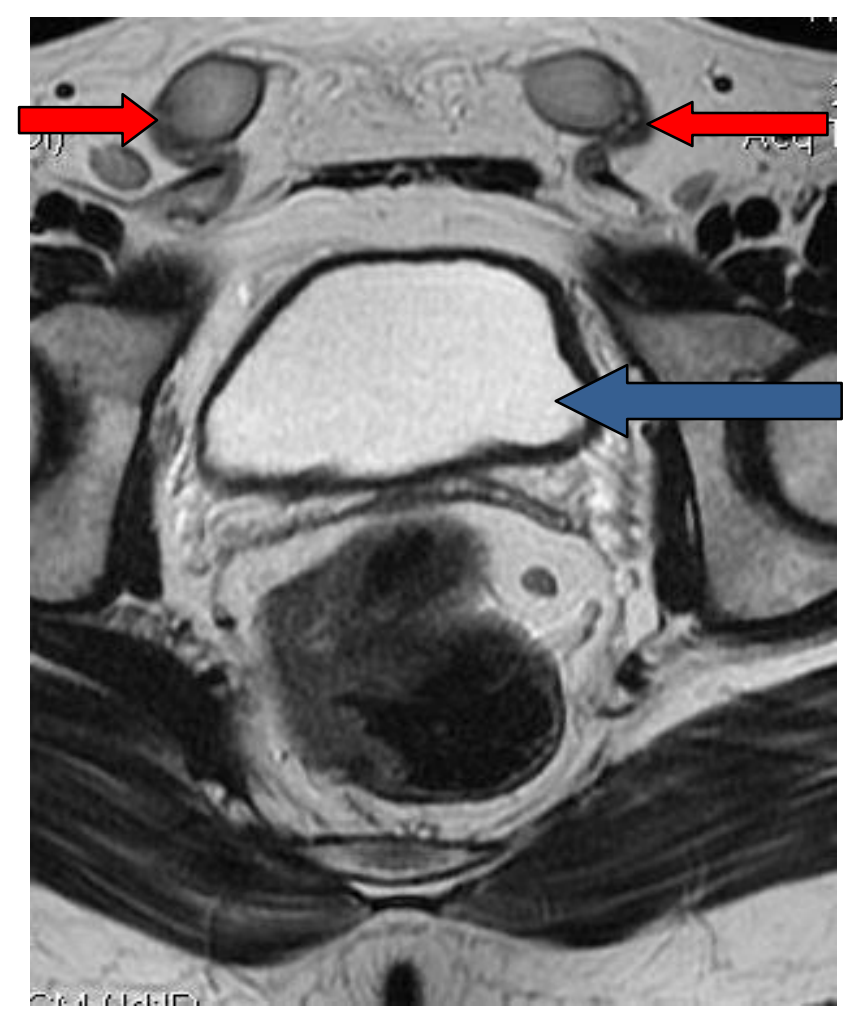

Fig 2:-Axial T2 W image of the pelvis showing two well defined lobulated soft tissue lesions ( Red arrows) in the bilateral inguinal canals suggestive of testis.Urinary bladder seen posteriorly( Blue arrow) 


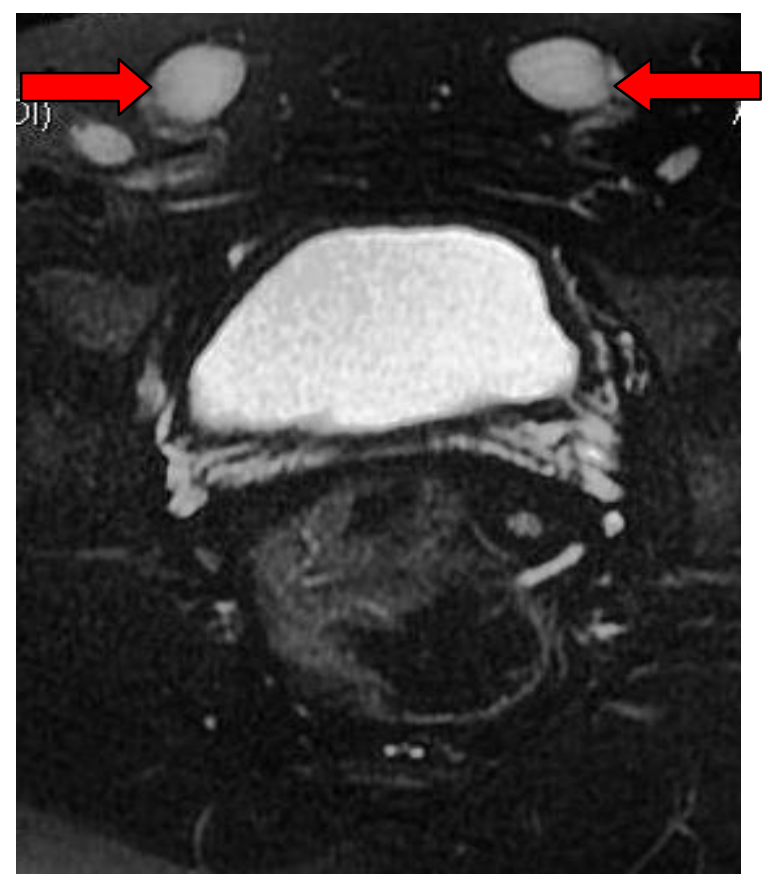

Fig 3:-Axial T1 W image of the pelvis showing similar features as above.

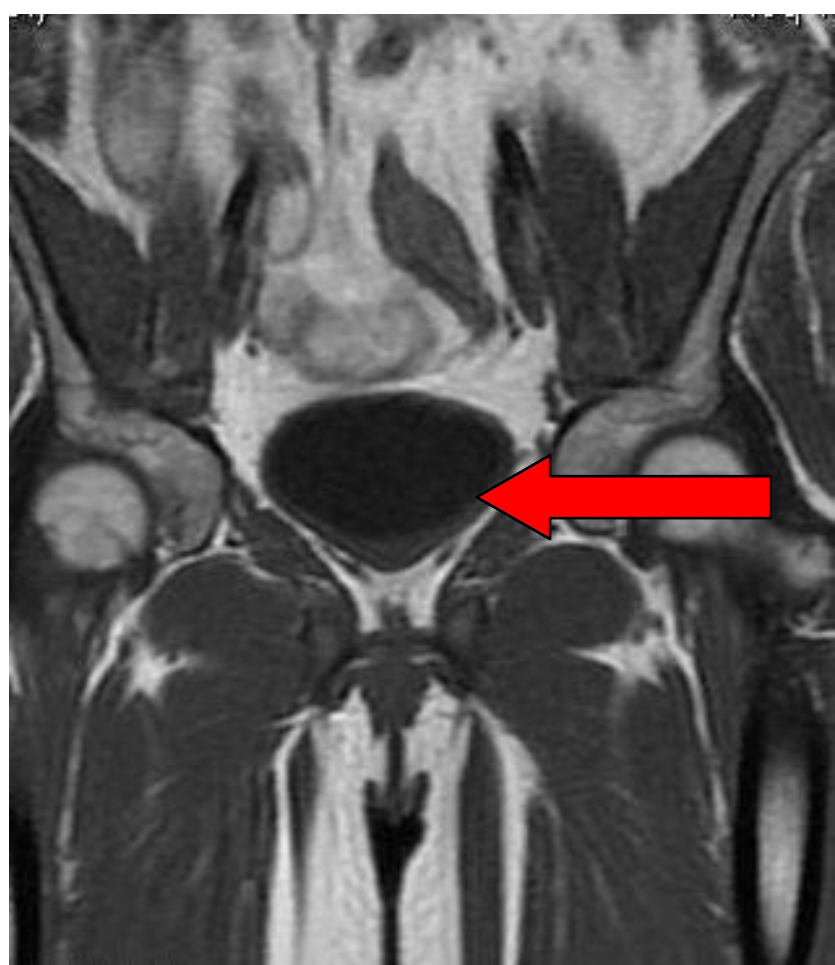

Fig 4:-Coronnal T2 W image of the pelvis showing urinary bladder ( Red arrow) with non -visualization of uterus and cervix. 


\section{References:-}

1. https://www.hindawi.com/journals/crira/2013/158484/

2. https://www.ncbi.nlm.nih.gov/pmc/articles/PMC4921180/

3. https://www.ncbi.nlm.nih.gov/pubmed/18330332

4. https://casereports.bmj.com/content/2016/bcr-2016-217229

5. https://radiopaedia.org/articles/androgen-insensitivity-syndrome

6. https://pubs.rsna.org/doi/10.1148/radiol.13121068 